J. Dairy Sci. 97:5387-5392

http://dx.doi.org/10.3168/jds.2014-8193

(C) American Dairy Science Association ${ }^{\circledR}, 2014$. Open access under CC BY-NC-ND license.

\title{
Short communication: Dairy consumption among middle-aged and elderly adults in Switzerland
}

\author{
Magali Chollet, ${ }^{* 1}$ Doreen Gille, ${ }^{*}$ Patrizia Piccinali, ${ }^{*}$ Ueli Bütikofer, ${ }^{*}$ Alexandra Schmid, ${ }^{*}$ Helena Stoffers, ${ }^{*}$ \\ Themistoklis Altintzoglou, $\dagger$ and Barbara Walther* \\ ${ }^{*}$ Agroscope, Institute of Food Sciences, $\mathrm{CH}-3003$ Bern, Switzerland \\ †Nofima, NO-9291 Tromsø, Norway
}

\begin{abstract}
Different studies have shown that people are aware of the benefits of dairy products, but a sizeable part of the world's population still does not consume the recommended amount of dairy produce. The aims of the present research were to determine which dairy products are consumed by the middle-aged and elderly (50-81 yr old) living in Switzerland and to explore why some of this population segment are actually reducing their consumption of dairy products. On average, older Swiss adults consumed 2.6 portions of dairy products per day, which is slightly less than the recommended 3 to 4 portions a day. Additionally, about one-quarter of the respondents indicated that they have reduced their milk or dairy consumption. The main reasons given for this decision were to reduce fat or cholesterol. A reported difficulty in digesting some dairy products may be a further reason for limiting dairy intake, particularly cheese. It follows that a need for the propagation of appropriate nutritional information about dairy products to the middle-aged and elderly exists.
\end{abstract}

Key words: elderly, middle-aged, dairy, consumption, Swiss

\section{Short Communication}

In Europe, the proportion of elderly people is increasing. By 2050, more than one-quarter $(27 \%)$ of the population is expected to be aged 65 yr or older. Better knowledge of health and nutritional status, as well as of appropriate nutritional behavior, might help to improve quality of life in the third and fourth ages of lifespan (Turconi et al., 2013).

Evidence exists that the public is aware of the importance of milk and its products, especially for the positive effects of its calcium content on bone metabolism (Wham, 2001; Bus and Worsley, 2003; Wham and Worsley, 2003; Davis and Katz, 2013). However,

Received April 1, 2014.

Accepted June 4, 2014.

${ }^{1}$ Corresponding author: magali.chollet@agroscope.admin.ch research has also shown that a significant proportion of the population still does not consume the recommended amount of dairy produce (Wham, 2001; Federal Department of Health, 2012; Stewart et al., 2013; Turconi et al., 2013). It is therefore important to identify which dairy products are consumed by the elderly, and to understand the motives underlying nonconsumption or reduced consumption.

\section{Participants and Study Design}

For the present study, the LINK Institute (Lucerne, Switzerland) selected a total of 726 Swiss residents, by means of a telephone recruiting interview, according to age and region (German speaking $=50.3 \%$, French speaking $=30.4 \%$, and Italian speaking $=19.3 \%$ ). For statistical reasons, the proportion of Italian-speaking participants was over-represented. The data were collected by printed questionnaire, or by electronic online questionnaire (30\%), between September and November 2012. The target group was consumers between 50 and $81 \mathrm{yr}$ old who were not living in a nursing home.

\section{Questionnaire}

The questionnaire comprised 4 sections. The first of these dealt with general questions about food and health [D. Gille, U. Bütikofer, M. Chollet, A. Schmid, T. Altintzoglou, P. Honkanen (Nofima, Troms $\varnothing$, Norway), H. Stoffers, B. Walther, and P. Piccinali; unpublished data]. The second section, focused on dairy products, is the subject matter of the current paper. The third part concerned meat products [A. Schmid, D. Gille, P. Piccinali, U. Bütikofer, M. Chollet, T. Altintzoglou, P. Honkanen (Nofima, Troms $\varnothing$, Norway), B. Walther, H. and Stoffers; unpublished data], and the final part sought personal data including sociodemographics. The questionnaire was made available in French, German, and Italian.

In the second part of the questionnaire, discussed herein, respondents were asked about their habitual dairy intake and their reasons for consuming these 
products. The first question established whether the respondent consumes milk or dairy products. If not, they were requested to proceed directly to the section dealing with meat products.

Respondents' intake of 11 different dairy products was measured on a 7-point frequency scale, as indicated in Figure 1. Where the participant consumed reducedfat dairy products, he or she had to specify the reason by choosing between "calories reduction," "reduction of fat intake," "better taste," "better texture," or "on recommendation from another person." In the next 3 questions, the consumer had to rate milk, yogurt, and cheese on 5-point Likert scales as healthy, safe, tasty, and easy to digest.

Respondents were asked whether they were reducing their consumption of (a) milk and (b) dairy products and, if so, to indicate their motives for doing so. Responses were recorded on 5-point Likert scale ratings of the following possible reasons: "because of changes in lifestyle (e.g., children left home)"; "do not tolerate it any more"; "do not like the taste any more"; "want to lose weight"; "want to reduce fat intake"; and "want to reduce cholesterol intake." Two additional responses were offered for dairy products: "to reduce salt intake" and "to reduce sugar intake." Explanatory variables included sociodemographics such as sex (categorical), age (continuous), education level (categorical), height, and weight (continuous).

\section{Data Analysis}

Questionnaires were analyzed using Systat13.0 (Systat Software Inc., Richmond, CA). Body mass index (BMI) was calculated as the ratio between weight $(\mathrm{kg})$ and height squared $\left(\mathrm{m}^{2}\right)$. To facilitate the statistical calculations, consumption frequency of dairy-based

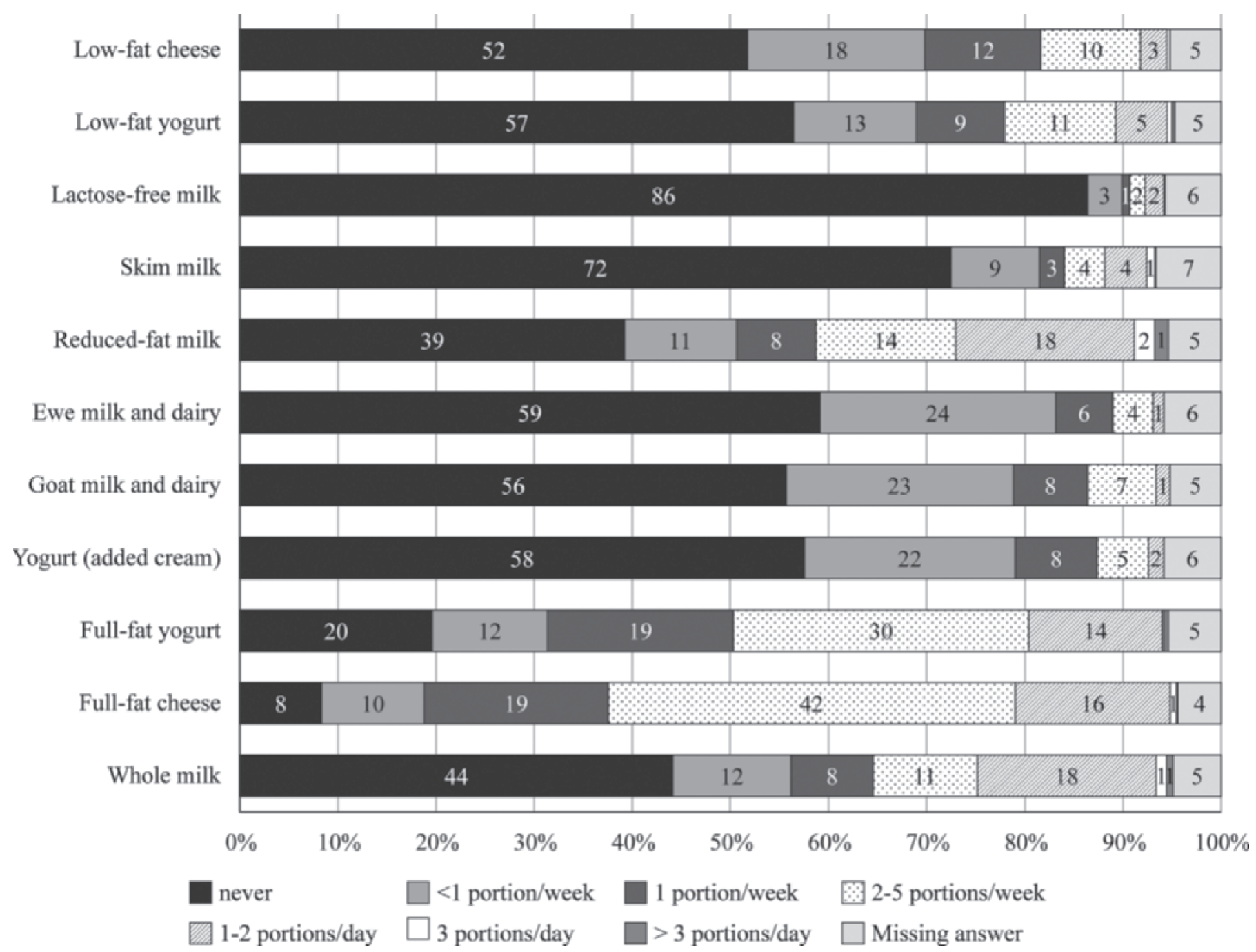

Figure 1. Consumption of dairy products by older adults living in Switzerland. (No values in the graph for data $<1 \%$ ). 
portions was transformed using the following scale: never $=0$; less than 1 portion $/$ wk $=0.5 ; 1$ portion $/$ $\mathrm{wk}=1 ; 2$ to 5 portions $/ \mathrm{wk}=3.5 ; 1$ to 2 portions $/ \mathrm{d}$ $=10.5 ; 3$ portions $/ \mathrm{d}=21$; more than 3 portions $/ \mathrm{d}=$ 28. One portion is taken to be equivalent to 1 glass of milk (2 dL), 1 cup of yogurt (180 g), or 30 to $60 \mathrm{~g}$ of cheese. Descriptive analyses were used to describe the dependent variables.

Differences $(P \leq 0.05)$ were analyzed using the Kruskal-Wallis test, and pairwise comparisons were conducted with the Conover-Inman Test to detect significant differences $(P \leq 0.05)$ between sex, spoken language (French, German, Italian), education level (low, medium, high), BMI $(\leq 25$ or $>25)$, and age (50-59, 60-69, and 70-81 yr old). For these tests, statements were converted to numerical values: not important at all $=1$; not very important $=2$; neither nor $=3$; quite important $=4$; very important $=5$. The answer "I do not know" and missing answers have not been taken into account.

\section{Results}

A total of 646 persons returned the questionnaire (89\%) and 14 surveys had to be excluded due to incompleteness or incorrect age (valid questionnaires $\mathrm{n}=$ 632). Table 1 describes the sociodemographic distribution of participants.

Of the 631 respondents to the question, 474 (75\%) consumed milk. More women and more French-speaking persons reported not drinking milk at all $(P=0.02$ and $P=0.0001$, respectively), but no significant influence of age, level of education, or BMI was observed. Of 630 respondents to the question, 607 consumed dairy products $(96 \%)$, and Italian-speaking people, in par- ticular, did not $(P=0.002)$. No significant influence of sex, age, level of education, or BMI was noted. Only 19 respondents $(3 \%)$ consumed neither milk nor dairy products.

Responses to the questions about frequency of dairy product consumption are summarized in Figure 1. On average, 18 portions of dairy products (including milk) were consumed per week, of which 7 portions were fat reduced. The most frequently consumed product was reduced-fat milk (2.7\% fat or less) at 4.5 portions per week, followed by full-fat cheese (3.7 portions), fullfat or fat-enriched yogurt (3.6 portions), whole milk (3 portions), low-fat yogurt (1.4 portions), and low-fat cheese (less than 1 portion per week). No significant differences were observed in the consumption of dairy products across sex, language, education, BMI, or age, with the exception of consumption of goat and ewe milk products or reduced-fat products. With increasing education and decreasing age, the consumption of goat and ewe milk products was higher $(P<0.05)$. In particular, goat dairy products were favored by Italian-speaking participants (Table 2), and ewe milk products by older adults with $\mathrm{BMI} \leq 25(P=0.048)$. Again, reduced-fat yogurt was more often eaten by women $(P=0.003)$, and low-fat cheese by older adults with BMI $>25(P=$ 0.03 ), as well as by Italian-speaking respondents (Table 2). Conversely, French-speaking respondents consumed more skim milk (0.1\% fat) and less low-fat milk (Table 2). Fifty-three percent of our respondents reported consuming reduced-fat products, for reasons including to reduce fat intake (84\%); to reduce intake of calories (59\%); better taste $(26 \%)$; on recommendation of another person (19\%); and better mouth feeling (17\%).

Respondents with a BMI > 25 more often mentioned reduction of calories or fat reduction as a reason for

Table 1. Characteristics of the 632 respondents

\begin{tabular}{lr}
\hline Item & $\mathrm{n}(\%)$ \\
\hline Total sample size & $632(100)$ \\
Sex & \\
Women & $323(51.1)$ \\
Men & $309(48.9)$ \\
Age & \\
$50-59$ yr & $254(40.2)$ \\
$60-69$ yr & $313(49.5)$ \\
$70-81$ yr & $65(10.3)$ \\
Language-region & $318(50.3)$ \\
German & $192(30.4)$ \\
French & $122(19.3)$ \\
Italian & $82(13.0)$ \\
Education & $280(44.3)$ \\
Low (compulsory school) & $248(39.2)$ \\
Medium (A-levels, professional education) & $16(2.5)$ \\
High (higher professional education, university of applied science, university) & $6(0.9)$ \\
Other & \\
No data &
\end{tabular}

${ }^{1}$ Not included in the statistical evaluation. 
Table 2. Portions of milk and dairy consumed per week according to the language of the respondents

\begin{tabular}{|c|c|c|c|c|c|c|c|}
\hline \multirow[b]{2}{*}{ Item (n) } & \multicolumn{2}{|c|}{$\begin{array}{c}\text { French } \\
(\mathrm{n}=182-192)\end{array}$} & \multicolumn{2}{|c|}{$\begin{array}{c}\text { German } \\
(\mathrm{n}=303-318)\end{array}$} & \multicolumn{2}{|c|}{$\begin{array}{c}\text { Italian } \\
(\mathrm{n}=108-122)\end{array}$} & \multirow[b]{2}{*}{$P$-value } \\
\hline & Mean & SD & Mean & SD & Mean & SD & \\
\hline Whole-fat milk & 2.99 & 4.95 & 2.83 & 5.01 & 3.39 & 4.54 & NS \\
\hline Full-fat cheese & 3.70 & 3.55 & 3.80 & 4.05 & 3.39 & 3.46 & NS \\
\hline Full-fat yogurt & 3.53 & 4.33 & 2.70 & 3.69 & 3.28 & 3.70 & NS \\
\hline Yogurt with added cream & 0.62 & 1.68 & 0.50 & 1.28 & 0.68 & 1.87 & NS \\
\hline Goat milk and dairy & $0.75^{\mathrm{b}}$ & 1.74 & $0.38^{\mathrm{a}}$ & 1.11 & $1.04^{\mathrm{c}}$ & 1.95 & $* * *$ \\
\hline Ewe milk and dairy & 0.61 & 1.56 & 0.36 & 1.06 & 0.47 & 1.49 & NS \\
\hline Low-fat milk & $2.51^{\mathrm{a}}$ & 4.57 & $4.05^{\mathrm{b}}$ & 6.19 & $3.97^{\mathrm{b}}$ & 5.48 & $* *$ \\
\hline Skim milk & $1.13^{\mathrm{b}}$ & 3.11 & $1.04^{\mathrm{a}}$ & 3.56 & $0.29^{\mathrm{a}}$ & 1.21 & $*$ \\
\hline Lactose-free milk & 0.35 & 1.75 & 0.21 & 1.44 & 0.63 & 2.42 & NS \\
\hline Low-fat yogurt & 1.72 & 4.15 & 1.34 & 2.99 & 0.76 & 1.93 & NS \\
\hline Low-fat cheese & $0.93^{\mathrm{a}}$ & 2.44 & $0.80^{\mathrm{a}}$ & 1.88 & $1.48^{\mathrm{b}}$ & 2.86 & $* * *$ \\
\hline Total & 18.02 & 13.49 & 17.40 & 12.33 & 17.33 & 12.04 & NS \\
\hline
\end{tabular}

${ }^{\mathrm{a}-\mathrm{c}}$ Means within a row with different superscript differ $(P<0.05)$.

${ }^{*} P<0.05 ;{ }^{* *} P<0.01,{ }^{* * *} P<0.001$.

consuming reduced-fat dairy $(P<0.05)$. Better taste was more often chosen by German-speaking respondents $(P=0.0001)$ and recommendation from another person by French-speaking participants $(P=0.01)$. French-speaking respondents less often reported reduced calorie intake as a reason $(P=0.0001)$. As to differences between the sexes, women more often agreed that reduced-fat dairy has a better taste $(P=0.047)$, and men more often answered that they consume reduced-fat dairy on the recommendation of another person $(P=0.032)$. Respondents between 50 and 59 yr old also more often specified taste as a reason for their consumption of reduced-fat dairy products $(P=$ 0.034). No significant influence of level of education on the intake of reduced-fat products was noted.

The majority of the participants considered milk, yogurt, and cheese as safe, healthy, and tasty (Table $3)$. These respondents also considered these products easy to digest, with the exception of milk (19\%) and cheese, which was perceived to be rather difficult or very difficult to digest by $29 \%$ (Table 3 ). In particular, respondents with higher educational attainment answered more often that milk $(P=0.000)$ or cheese $(P=0.01)$ are difficult to digest and also rated the healthiness of cheese as lower than respondents with lower educational attainment $(P=0.016)$. Healthiness, tastiness, and digestibility for milk and yogurt $(P<0.05)$, as well as the tastiness of cheese $(P=$ $0.000)$, were more often rated lower by French-speaking respondents, but German-speaking older adults more often indicated that cheeses are difficult to digest $(P=$ 0.000). Elderly respondents between 70 and 81 yr old more often reported that cheese is healthy $(P=0.016)$ or easy to digest $(P=0.010)$.

Across all respondents, $172(27 \%)$ indicated that they were actually reducing their liquid milk consumption and 158 (25\%) reported a reduction in their dairy intake. The 2 main reasons for this lowered consumption of milk and dairy were to reduce fat intake (47 and $62 \%$, respectively) or to reduce cholesterol intake (48 and 59\%, respectively). Of these, $40 \%$ reduced milk intake because of intolerance, and $34 \%$ because of changes of lifestyle. Reduction of BW was mentioned by $29 \%$ and dislike of taste by $23 \%$.

Table 3. Percentage of respondents who agreed or disagreed that milk, yogurt, and cheese are healthy, safe, tasty, and easy to digest

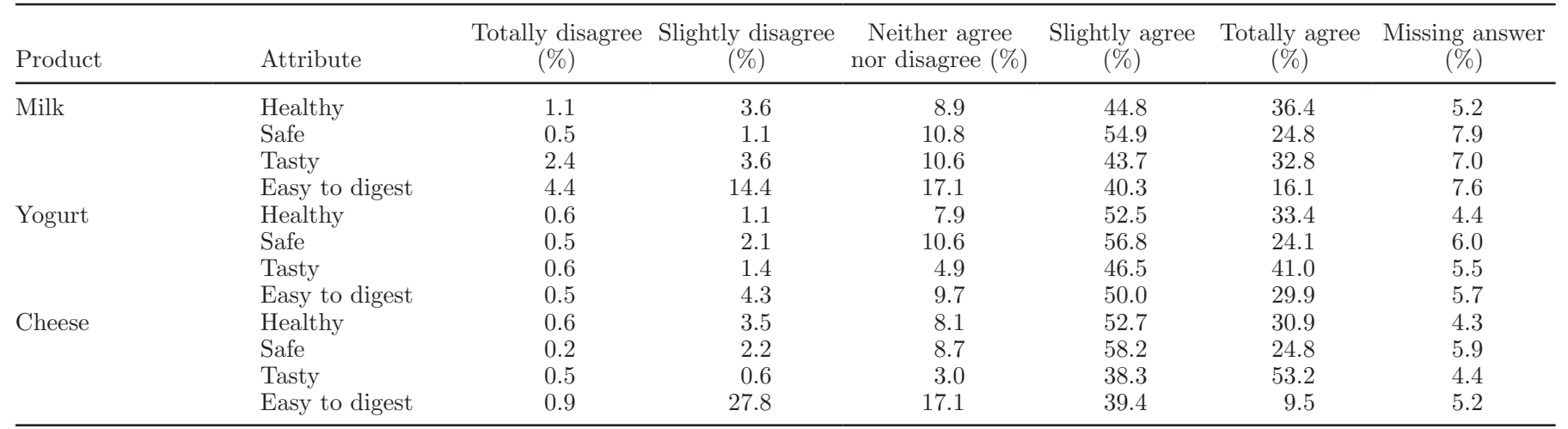


More middle-aged and elderly respondents with BMI $>25$ reported reducing their milk consumption to reduce weight $(P=0.005)$. Italian-speaking respondents indicated more often than German- and French-speaking respondents that they drink less milk to reduce cholesterol intake $(P=0.003)$. No significant influence of level of education, sex, or age was seen.

Further reasons for limiting dairy intake (excluding milk) were (a) reduction of $\mathrm{BW}(45 \%)$; (b) reduction of sugar intake $(43 \%)$; and (c) reduction of salt intake $(38 \%)$. Changes in lifestyle were cited by $34 \%$, and intolerance for dairy products by $20 \%$; the latter reason was more often mentioned by women than by men ( $P$ $=0.045)$. Italian-speaking participants, by comparison with respondents from other Swiss regions, also more often reduced their consumption of dairy products to reduce their salt or sugar intake $(P=0.005$ and $P$ $=0.018$ respectively). With increasing age, cholesterol reduction was more frequently advanced as a reason for reducing consumption of dairy products $(P=0.026)$. Among respondents between 50 and 59 yr old, changes in lifestyle were reported more often than by older respondents as a reason for reducing dairy consumption $(P=0.012)$. No significant differences were observed in reduction of intake of dairy products in respect of level of education or BMI.

\section{Slightly Too Low Dairy Consumption}

According to the sixth Swiss nutrition report (Federal Department of Health, 2012), the percentage of the population consuming no milk or dairy products has increased in recent years - a trend also observed in the United States (Federal Department of Health, 2012; Stewart et al., 2013). The present findings indicate that only $3 \%$ of respondents aged 50 to 81 yr old neither drink milk nor consume dairy products, slightly less than the $5 \%$ of the total Swiss population documented in the Swiss nutrition report (Federal Department of Health 2012).

In the present case, milk contributed significantly to the total intake of dairy products, followed by yogurt and cheese. On average, 2.6 portions of dairy products are consumed per day (18 portions per week), which is slightly less than the recommended 3 to 4 portions per day for elderly people (Swiss Society for Nutrition, 2011). Only $32 \%$ of respondents here reported consuming 3 or more portions of dairy products per day, although this is still more than the $10 \%$ of the total Swiss population documented in the Swiss nutrition report (Federal Department of Health, 2012). An explanation may be that elderly people are more affected by osteoporosis and may therefore be more aware of the importance of calcium provided by dairy products.

\section{Consumption of Low-Fat Dairy Products}

A study of students in Norway, Denmark, and California showed that fat content, healthiness, and taste were the most important motivators for choosing energy-reduced dairy products (Johansen et al., 2011). In our study, $53 \%$ of respondents reported consuming reduced-fat products, principally to reduce fat consumption (84\%) and to reduce calories (59\%), with better taste cited by only $26 \%$.

Excepting milk, a general preference exists for full-fat dairy products among older adults in Switzerlandindeed, 10 portions of full-fat dairy products (milk, yogurt, cheese) are consumed on average per week, compared with 7 portions of reduced-fat products. In the United States, as well, figures of consumption are higher for low-fat milk than for full-fat milk (Stewart et al., 2013). Consumption of whole milk was similar across all regions of Switzerland, but elderly Frenchspeaking participants indicated that they consumed less milk that is partially fat reduced, but more skim milk, than German-speaking and Italian-speaking respondents. This preference for skim milk among French-speaking respondents seems to contradict the finding that these respondents less often reported liking the taste of reduced-fat dairy or wanting to reduce their calorie intake by consuming reduced-fat dairy. Conversely, French-speaking respondents did not eat more reduced-fat cheese or yogurt than respondents from other regions. It would be interesting, therefore, to know in which form older French adults consume skim milk - for example, in coffee or on its own.

In the present study, no difference was found between men and women in consumption of partially reducedfat milk. This conflicts with findings from an Australian study where reported consumption of reduced-fat milk was higher among women (Bus and Worsley, 2003). According to our survey, women consume significantly more reduced-fat yogurt than men. This finding was noted in an earlier Swiss study (Beer-Borst et al., 1994). By way of explanation, some authors proposed that women focus much more on fat content and weight control than men (Rozin et al., 1999; Johansen et al., 2011). Interestingly, in our study, both sexes reported choosing reduced-fat products to reduce fat intake or calories, with no significant sex difference; neither was any significant difference present between men and women in terms of concern about fat in dairy products (results not shown). Instead, women mentioned more often choosing reduced-fat products because they prefer the taste. It is therefore plausible that some women over 50 yr old consume reduced-fat yogurt because of the taste, rather than because they are more focused on weight control. 


\section{Reasons for Reduced Consumption of Dairy Products}

Twenty-three percent of older adults reported reducing their milk consumption and $25 \%$ reported reduced consumption of dairy products by comparison with earlier periods of their lives. Their main purpose was to reduce cholesterol or fat intake or both. As both components were in the past identified as risk factors for the development of coronary heart disease, it seems likely that more elderly people may still believe this. In fact, most of the current research does not link a high dairy intake with an increased risk for coronary heart disease (FAO, 2013).

Several studies have reported that respondents associate dairy with an increase in BW (Wham, 2001; Bus and Worsley, 2003; Nolan-Clark et al., 2011). Respondents with $\mathrm{BMI}>25$, in particular, indicated that they had reduced milk consumption to reduce their BW. This behavior may be explained by the fact that, among 42 countries that recommend consumption of dairy products, 26 favor low-fat or fat-free milk (FAO, 2013). According to other authors, the empirical evidence does not support the hypothesis that fat or high-fat dairy foods contribute to obesity (Dougkas et al., 2011; Kratz et al., 2013). In Switzerland, the recommendations for dairy products intake were adapted in 2011, whereas the advice favoring reduced-fat milk and dairy products was removed (Swiss Society for Nutrition, 2011). It seems likely, however, that this information has not yet been taken on board by the population at large.

One factor that may contribute to more limited dairy intake is individual difficulty in digesting dairy products. According to our survey, more elderly people had problems with the digestion of cheese $(29 \%)$, as compared with milk (20\%) and yogurt (5\%). Among the 119 respondents who had decreased their milk consumption, $40 \%$ reported that they had developed intolerance to milk. In respect to dairy products, $20 \%$ of the 106 respondents reported changing their habits of consumption because of dairy intolerances.

Nevertheless, most older respondents here considered milk, yogurt, and cheese as safe and healthy, and they did not report reducing their dairy intake. Specifically, when asked about their concerns about dairy products, only $4 \%$ were very concerned about fat content, whereas $24 \%$ were slightly concerned - a fact reflected in the higher intake of whole-fat dairy portions (10) as compared with reduced fat (7) in Switzerland.

A strength of the present study is the large age range, 50 to 81 yr, which yields important information about a part of the population that will continue to increase in the near future and is not usually considered in surveys. Conversely, the relevance of any overarching conclusions must be tempered by the fact that the current study was limited to Swiss citizens.

\section{Conclusions}

The majority of participants in our study did not consume the recommended amount of dairy products. Additionally, a significant part of the population is reducing consumption of dairy products for reasons that are not scientifically supported. Information campaigns specifically targeting the middle-aged and elderly are needed to increase their awareness of the nutritional value of dairy products, and their role in a healthy diet.

\section{REFERENCES}

Beer-Borst, S., Z. Puhan, and R. Amado. 1994. Konsum von Milch und Milchprodukten in der Schweiz. Ergebnisse einer Ernährungserhebung. Schweiz. Milchwirtsch. Forsch. 23:31-36.

Bus, A. E. M., and A. Worsley. 2003. Consumers' health perceptions of three types of milk: A survey in Australia. Appetite 40:93-100.

Davis, B., and B. Katz. 2013. Advances in Dairy Ingredients. WileyBlackwell, Oxford, UK.

Dougkas, A., C. K. Reynolds, I. D. Givens, P. C. Elwood, and A M. Minihane. 2011. Associations between dairy consumption and body weight: A review of the evidence and underlying mechanisms. Nutr. Res. Rev. 24:72-95.

FAO. 2013. Milk and dairy products in human nutrition. Accessed Jun. 24, 2014. http://www.fao.org/docrep/018/i3396e/i3396e.pdf.

Federal Department of Health. 2012. 6th Swiss Nutrition Report. Federal Department of Health, Bern, Switzerland.

Johansen, S. B., T. Naes, and M. Hersleth. 2011. Motivation for choice and healthiness perception of calorie-reduced dairy products. A cross-cultural study. Appetite 56:15-24.

Kratz, M., T. Baars, and S. Guyenet. 2013. The relationship between high-fat dairy consumption and obesity, cardiovascular, and metabolic disease. Eur. J. Nutr. 52:1-24.

Nolan-Clark, D. J., E. Neale, Y. Probst, K. Charlton, and L. Tapsell. 2011. Consumers' salient beliefs regarding dairy products in the functional food era: A qualitative study using concepts from the theory of planned behaviour. BMC Public Health 11:843.

Rozin, P., C. Fischler, S. Imada, A. Sarubin, and A. Wrzesniewski. 1999. Attitudes to food and the role of food in life in the USA, Japan, Flemish Belgium and France: Possible implications for the diet-health debate. Appetite 33:163-180.

Stewart, H., D. Dong, and H. Carlston. 2013. Why Are Americans Consuming Less Fluid Milk? A Look at Generational Differences in Intake Frequency. USDA Economic Research Report Number 149. USDA Economic Research Service, Washington, DC.

Swiss Society for Nutrition. 2011. Swiss Food Pyramid. Société Suisse de Nutrition, Bern, Switzerland. Accessed June 24, 2014. http:// www.sge-ssn.ch/media/medialibrary/2013/03/_sge_merkblaetter _pyramid_basic_e.pdf.

Turconi, G., M. Rossi, C. Roggi, and L. Maccarini. 2013. Nutritional status, dietary habits, nutritional knowledge and self-care assessment in a group of older adults attending community centres in Pavia, Northern Italy. J. Hum. Nutr. Diet. 26:48-55.

Wham, C. 2001. Demographic differences in usage and attitudes to milk. J. N. Z. Diet. Assoc. 55:18-21.

Wham, C. A., and A. Worsley. 2003. New Zealanders' attitudes to milk: Implications for public health. Public Health Nutr. 6:73-78. 